\title{
COMPORTAMENTO ALIMENTAR DE AVES EM CECROPIA (MORACEAE), EM MATA ATLÂNTICA, NO ESTADO DE SÃO PAULO
}

Luiz Octavio Marcondes-Machado ${ }^{1}$ Maria Martha Argel de Oliveira ${ }^{2}$

\begin{abstract}
This study is based on observations of behaviour of the bird species which visit and feed on 2 species of Cecropia catkins in three localities of the Atlantic forest, SP. A total of 31 species was observed visiting Cecropia; out of these, 17 were seen feeding on the catkins. Two species of the family Psittacidae were observed as seed predators. Seed germination tests of the seeds obtained from the birds' feces eating C. adenopus catkins proved that they function as dispersal agents.
\end{abstract}

\section{INTRODUÇÃO}

A dispersão de sementes de plantas do gênero Cecropia por aves tem sido estudada por alguns autores como Einsenmann (1961), Leck (1972a, 1972b), Trejo Pérez (1976), Silva (1980), e Sazima et al. (1981). Einsenmann (1961) observou que, no Panamá, poucas árvores possuem frutos tão procurados pelas aves quanto C. mexicana, da qual se alimentam 22 espécies.

Espécies do gênero Cecropia ocorrem na região netropical (Snow, 1981), em clareiras naturais ou provocadas por atividade humana (Válio \& Joly, 1979), bem como em florestas secundárias (Joly, 1970). Estudos experimentais revelaram que sementes de G. glaziovii Snethlage são fotossensitivas (Válio \& Joly, 1979), o mesmo ocorrendo, possivelmente, com sementes de outras espécies.

O presente estudo teve por finalidade verificar quais aves se alimentam das infrutescências de Cecropia na região de mata atlântica no estado de São Paulo, observando-se seu comportamento. Além disso procurou-se avaliar a importância das aves na dispersão de sementes de Cecropia.

1. Departamento de Zoologia, Universidade Estadual de Campinas.

2. Pós-Graduação em Ecologia, Universidade Estadual de Campinas. 
Nessa região do Estado de São Paulo ocorrem duas espécies do gênero, $C$. adenopus e C. glaziovii, conhecidas popularmente como embaúbas. Ambas são árvores de porte elevado, com grandes folhas lobadas e troncos com anéis; possuem pedúnculos femininos providos de várias espigas alongadas.

\section{MATERIAL E MÉTODOS}

As observações foram realizadas em um sítio no município de Juquiá e em duas localidades do município de São Sebastião. Todos os locais estão situados em regiões originalmente recobertas por Mata Atlântica, no Estado de São Paulo. A seguir são descritos os locais, as plantas estudadas e o ambiente circundante.

O sítio de Juquiá está situado na Serra dos Itatins, separado do litoral por esta e pela Serra da Juréia. Nesse local foi estudada uma planta de Cecropia cf. glaziovii composta por três hastes, ao todo com aproximadamente 40 pedúnculos de infrutescências e com altura entre 5 e $6 \mathrm{~m}$. A planta estava localizada a cerca de $25 \mathrm{~m}$ da borda de uma mata e a uns 10 $\mathrm{m}$ de um pequeno bananal, separado da mata por uma área de vegetação herbáceo-arbustiva. As observações foram realizadas de 10 a 12 de dezembro de 1983.

No distrito de Boissucanga, município de São Sebastião, foi observado um grupo de 16 exemplares de $C$. adenopus, de aproximadamente $10 \mathrm{~m}$ de altura, localizada na beira de uma mata pluvial de encosta. O período de observação foi de 25 a 30 de janeiro de 1984 .

O terceiro local, localizado também no município de São Sebastião, é a área ocupada pelo Centro de Biologia Marinha (CEBIMAR), onde existe um resquício de mata. Em 15 e 16 de junho de 1984 e entre 25 e 29 de junho de 1985 foram estudados 4 exemplares de Cecropia cf. adenopus, um com cerca de $2 \mathrm{~m}$ e outros três com 6 a $7 \mathrm{~m}$ de altura. As plantas encontram-se em uma encosta no ecótono entre vegetação herbácea e a mata, situada logo abaixo.

Foram empregados nas observações binóculos Daiko 8 x 40 (no CEBIMAR e em Juquiá) e Kamakura Kohki 10 x 15 (Boissucanga).

Em Boissucanga, as fezes de aves encontradas sob a copa das árvores estudadas e nos arredores foram coletadas. As sementes de $C$, adenopus nelas contidas foram triadas, lavadas e postas para germinar em placa de Petri sobre papel de filtro umedecido, sob luz natural.

\section{RESULTADOS}

As espécies de aves observadas visitando Cecropia sp. nos diferentes locais, totalizaram 31 , das quais 17 foram vistas alimentando-se de infrutescências. Tais espécies são listadas a seguir. A nomenclatura seguida é a adotada por Meyer de Schauensee (1970). 


$\begin{array}{ll}\text { Famnlia Columbidae: } & \begin{array}{l}\text { Columba plumbea Vieillot } \\ \text { Columbina talpacoti } \text { Temminck }\end{array} \\ \text { Familia Psittacidae: } & \begin{array}{l}\text { Forpus xanthopterygius (Spix) } \\ \text { Brotogeris tirica (Gmelin) } \\ \text { Pionus maximiliani (Kuhl) }\end{array} \\ \text { Família Picidae: } & \text { Melanerpes flavifrons (Vieillot) } \\ \text { Família Pipridae: } & \begin{array}{l}\text { Chiroxiphia caudata (Shaw \& Nodder) } \\ \text { Manacus manacus (Linnaeus) }\end{array} \\ \text { Família Tyrannidae: } & \begin{array}{l}\text { Satrapa icterophrys (Vieillot) } \\ \text { Tyrannus melancholicus (Vieillot) } \\ \text { Myiodynastes maculatus P.L.S. Müller) }\end{array} \\ & \begin{array}{l}\text { Myiozetes similis (Spix) } \\ \text { Pitangus sulphuratus (Linnaeus) } \\ \text { Attila } \text { sp. } \\ \text { Camptostoma obsoletum (Temminck) }\end{array}\end{array}$

Família Turdidae: $\quad$ Platycichla flavipes (Vieillot)

Turdus rufiventris Vieillot

Turdus amaurochalinus Cabanis

Família Vireonidae: $\quad$ Vireo olivaceus Linnaeus

Família Parulidae: $\quad$ Parula pitiayumi Vieillot)

Família Coerebidae: Coereba flaveola (Linnaeus)

Dacnis cayana (Linnaeus)

Família Thraupidae: $\quad$ Tangara seledon (P.L.S. Müller)

Thraupis sayaca (Linnaeus)

Thraupis ornata (Sparrman)

Thraupis palmarum (Wied)

Ramphocelus bresilius (Linnaeus)

Tachyphonus rufus (Boddaẹt)

Tachyphonus coronatus (Vieillot)

Thlypopsis sordida (Lafresnaye \& d'Orbigny)

Família Fringillidae: Zonotrichia capensis (P.L.S. Müller)

Na tabela 1 estão as informações sobre as localidades em que cada espécie foi observada. Também estão relacionadas quais as espécies vistas alimentando-se das infrutescências de Cecropia sp.

\section{Comportamento alimentar}

Os indivíduos de $F$. xanthopterygius, em geral presentes em bandos com até 9 indivíduos, pousam na própria infrutescência, de cabeça para baixo, e retiram pedaços, nem sempre da extremidade distal; podem também pousar em um galho próximo para comer; enquanto os indivíduos se alimentam ouve-se um barulho característico, possivelmente devido à 
Tabela 1

Espécies de aves observadas em Cecropia spp, em localidades da Serra do Mar, no Estado de São Paulo.

\begin{tabular}{|c|c|c|c|}
\hline Espécie & 1 & 2 & 3 \\
\hline Columba plumbea & & & na \\
\hline Columbina talpacoti & & & na \\
\hline Forpus xanthopterygius & & & a \\
\hline Brotogeris tirica & & a & \\
\hline Pionus maximiliani & & na & \\
\hline Melanerpes flavifrons & a & a & \\
\hline Chiroxiphia caudata & a & & \\
\hline Manacus manacus & a & & \\
\hline Satrapa icterophrys & & & na \\
\hline Tyrannus melancholicus & na & & \\
\hline Myiodynastes maculatus & a & & \\
\hline Myiozetetes similis & na & & na \\
\hline Pitangus sulphuratus & & & a \\
\hline Attila sp & na & & \\
\hline Comptostoma obsoletum & & & na \\
\hline Platycichla flavipes & & a & \\
\hline Turdus rufiventris & a & a & na \\
\hline Turdus amaurochalinus & & na & na \\
\hline Vireo olivaceus & a & & \\
\hline Parula pitiayumi & & & na \\
\hline Coereba flaveola & & na & \\
\hline Dacnis cayana & a & & \\
\hline Tangara seledon & a & & \\
\hline Thraupis sayaca & a & & a \\
\hline Thraupis ornata & & a & \\
\hline Thraupis palmarum & a & a & a \\
\hline Ramphocelus bresilius & a & a & a \\
\hline Tachyphonus rufus & & na & \\
\hline Tachyphonus coronatus & na & & \\
\hline Thlypopsis sordida & & & na \\
\hline Zonotrichia capensis & & & na \\
\hline
\end{tabular}

1. Município de Juquiá (10-12 de dezembro de 1983) C. cf. glaziovii

2. Distrito de Boissucanga, São Sebastião (25-30 de janeiro de 1984) C. adenopus.

3. Centro de Biologia Marinha (CEBIMAR), São Sebastião (15-16 de junho de 1984 e 25-29 de junho de 1985) $C$. cf. adenopus.

a - ave observada alimentando-se de infrutescência

na - ave não observada alimentando-se

maceração das sementes. Em 15-16 de junho de 1984 a presença de $F$. xanthopterygius era constante nas plantas em observação; já no ano seguinte ( 25 a 29 de junho de 1985), as aves não foram vistas nessas plantas, mas sempre em outras embaúbas próximas.

B. tirica também pousa próximo ou em uma infrutescência, por vezes de cabeça para baixo. Ao retirar um pedaço, tritura as sementes mandibulando-as; durante esse processo deixa cair vários fragmentos da 
infrutescência. Em algumas ocasiões indivíduos voam com pedaços grandes, com aproximadamente $1 / 3$ do tamanho total da espiga. Foram observados grupos com até 8 indivíduos alimentando-se juntos.

M. flavifrons se alimenta pousando sobre a infrutescência e desferindo golpes rápidos com o bico, como se estivesse bicando um tronco em busca de insetos, arrancando e engolindo os pedaços.

Um indivíduo de $C$. caudata foi visto partindo de um galho para retirar em vôo, um pedaço de polpa, que comeu após pousar novamente.

Além de alguns machos de $M$. manacus foram observados diversos indivíduos de colorido verde-oliváceo, provavelmente tanto fêmeas quanto imaturos; era comum o aparecimento simultâneo na planta de dois ou mais indivíduos oliváceos, mas nunca foi observado mais de um macho em um determinado instante. Os indivíduos pousam em um gaIho, em outra infrutescência ou na mesma de que se alimentam; ao pousarem em uma infrutescência, podem ficar paralelos a ela ou transversalmente. Foram vistos pousar em um galho, voar até uma infrutescência, na qual pousam para retirar um pedaço, e daí voltar ao galho antes de comer. Em uma ocasião foi visto um indivíduo oliváceo que retirava, com o bico, fragmentos da espiga, com os quais alimentava outros dois indivíduos, provavelmente filhotes, que permaneciam pousados em um galho próximo.

Um indivíduo de $M$. maculatus, visto apenas uma vez, pousou em um galho e daí partiu para um vôo em direção a uma infrutescência; sem pousar retirou um pedaço, que só comeu após retornar ao galho.

$P$. sulphuratus foi vista várias vezes pousando em galhos próximos à infrutescência, das quais se alimentou. Nunca mais de um indivíduo da espécie pousava na planta em um dado instante.

$P$. flavipes e $T$. rufiventris se alimentam de maneira semelhante: voam até a infrutescência, apreendem um pedaço com o bico, deixam-se cair, arrancando o pedaço, e pousam em um pecíolo da própria árvore, antes de ingeri-lo. Podem também pousar sobre a infrutescência, arrancar um pedaço com o bico e voar até um pecíolo ou um galho próximo, onde engolem a porção arrancada.

Quanto a $V$. olivaceus, foi observado apenas um indivíduo, alimentando-se de pedaços de infrutescências. Foi visto também capturando insetos ao voar de um galho a outro de uma planta.

Indivíduos de $D$. cayana visitam as plantas isoladamente ou em casais; pousam em uma infrutescência transversalmente a ela, retirando porções de outra espiga do mesmo pedúnculo. Um indivíduo foi visto alimentando-se assim e depois voando para um galho com um pedaço no bico, que ingeriu a seguir.

$T$. seledon chegou à planta, retirou um pedaço de infrutescência e rapidamente partiu, tendo sido isto observado apenas uma vez.

$T$. sayaca, $T$. ornata, $T$. palmarum e $R$. bresilius apresentam o mes- 
mo comportamento alimentar. Pousam ou sobre a infrutescência ou em um galho ou pecíolo próximo a ela e arrancam pedaços que engolem, podendo deixar cair vários antes de engolir um. T. palmarum foi observado pousado na infrutescência de cabeça para baixo, arrancando alguns pedaços da extremidade distal e afastando-se em seguida para outras árvores.

Um macho e uma fêmea de $T$. coronatus foram vistos visitando a planta, juntos ou separadamente. Seu comportamento alimentar é semelhante ao de outros traupídeos, e indivíduos são observados, como $T$. palmarum, pousando em infrutescências de cabeça para baixo. Em três ocasiões a fêmea foi observada afastando-se da planta com porções de infrutescência no bico, padrão também observado para o macho, em uma vez.

Em Juquiá, a maioria das aves chegava à Cecropia vindas da direção do bananal ou por uma rota paralela à borda da mata; não foi observada nenhuma ave vinda da mata, embora em algumas ocasiões, ao partirem, as aves se dirigissem para lá. Em Boissucanga, todas as aves que foram vistas visitando as árvores afastavam-se após se terem alimentado, ou indo para o interior da mata ou permanecendo nas árvores da região do ecótono, entre a área desmatada e a mata. Às vezes podiam se alimentar também em uma árvore de Trema micrantha Blume, localizada nos arredores. Na área do CEBIMAR, as aves voavam às plantas em observação tanto a partir da mata, situada na encosta, logo abaixo, quanto de áreas mais abertas, na encosta acima das embaúbas. Em 1985 algumas espécies que no ano anterior freqüentavam assiduamente as plantas, como por exemplo $P$. sulphuratus, eram vistas comumente alimentando-se dos frutos de uma Rapanea sp localizada a cerca de $15 \mathrm{~m}$ das plantas em observação.

As espécies que mais visitaram e efetivamente se alimentaram das infrutescências em cada lugar foram: em Juquiá, $T$. sayaca e $M$. manacus; em Boissucanga, $B$. tirica e $T$. palmarum no CEBIMAR, $F$. xanthopterygius foi a espécie vista com maior freqß̈encia em 1984, mas no ano seguinte foi $T$. sayaca, sendo o psitacídeo raramente visto.

\section{Encontros agressivos}

Alguns encontros agressivos interespecíficos foram observados entre os indivíduos que visitaram Cecropia. Em Juquiá, diversas espécies como $T$. rufiventris, $T$. sayaca, $R$. bresilius, $T$. coronatus, ocasionaram a fuga de $M$. manacus; $T$. sayaca afugentou ainda a $T$. coronatus; $T$. rufiventris a $T$. coronatus e a $T$. sayaca; $T$. coronatus a $T$. rufiventris.

Em Boissucanga, $T$. rufiventris ocasionou a fuga de $T$. palmarum $\mathrm{e}$ $B$. tirica causou a fuga de $P$. flavipes.

No CEBIMAR $T$. sayaca provocou a fuga de $R$. bresilius e de $P$. sulphuratus, e um $T$. palmarum afugentou um $T$. sayaca. 
Quanto a encontros intraespecíficos, o número foi bastante reduzido; em Juquiá ocorreram dois entre indivíduos de $M$. manacus e um envolvendo dois $T$. sayaca; em Boissucanga, houve apenas um, entre dois $B$. tirica que se alimentavam em uma mesma infrutescência, terminando com a fuga de um deles; por fim no CEBIMAR houve apenas a ocorrência de um encontro agressivo entre dois $F$. xanthopterygius, causando a fuga de um deles.

\section{Germinação de sementes}

Sob as plantas de $C$. adenopus, em Boissucanga, foram encontradas fezes de aves, sementes soltas e pedaços de frutos. Fezes com sementes de Cecropia foram também encontradas sob uma árvore de Trema micrantha distante uns $40 \mathrm{~m}$ do local das observações. Estas fezes foram triadas, sendo separadas 32 sementes de $C$. adenopus, cuja germinação em laboratório teve um sucesso de $65,7 \%$ (20 sementes).

\section{DISCUSSÃO E CONCLUSÃO}

As espécies do gênero Cecropia estão entre as plantas que oferecem alimento abundante durante todo o ano, sendo utilizada como recurso alimentar tanto por aves "frugívoras oportunistas", que se alimentam principalmente de insetos (Trejo Pérez, 1976), como por um grande número de espécies predominantemente frugivoras, ambos os grupos potencialmente importantes para sua dispersão.

M. flavifrons foi observada se alimentando em C. adenopus, o que vem confirmar o hábito alimentar, também frugívoro, de representantes da família Picidae, sendo este gênero o mais frugívoro da família, que é caracteristicamente insetívora, como já observada por Eisenmann (1961) em C. mexicana. No sistema evolutivo ave-planta, as aves que se alimentam de frutos promovem, através de dispersão, um aumento do número de árvores e conseqëntemente da produção de frutos, diminuindo a competição entre elas e permitindo que várias espécies possam se utilizar desse recurso (Morton, 1973). No entanto, algumas espécies de aves se alimentam de frutos para obter as sementes neles contidas, não contribuindo no desenvolvimento evolutivo da relação planta/ave (Snow, 1971), pois não dispersam as sementes (Morton, 1973). Incluído neste grupo de predadores de sementes estão os psitacídeos, considerados mais destruidores de sementes, porque as trituram e digerem, do que dispersores (Janzen, 1981; Jordano, 1983). Das espécies observadas, apenas B. tiri$c a$, apesar de triturar as sementes, voava com pedaços de fruto no bico, podendo eventualmente dispersá-las desta maneira.

Todas as outras espécies observadas engolem pedaços da polpa com 
sementes, que são pequenas, representando uma estratégia da planta para assegurar a dispersão. Desta maneira há alimento para dispersores e a eficiência da dispersão será maior, pois haverá mais sementes ingeridas (Trejo Pérez, 1976), aumentando a probabilidade de serem eliminadas com as fezes, em locais com claridade suficiente (Válio \& Joly, 1979).

As espécies vistas com maior freqüência se alimentando foram $B$. $t i$ rica e $F$. xanthopterygius, que são predadoras de sementes, e $T$. palmarum; esta se alimenta das espigas de outras espécies do gênero Cecropia, como C. mexicana (Eisenmann, 1961), C. concolor Willdenow (Silva, 1980) e C. glaziovi (Sazima et al., 1981), e habita as orlas das matas e matas secundárias (Phelps \& Meyer de Schauensee, 1978), locais com insolação maior, o que possibilita a germinação de sementes de Cecropia. Todas as outras espécies dispersoras observadas também habitam o mesmo tipo de ambiente, mais aberto, mostrando a coevolução existente entre o dispersor e a planta, que assim tem suas chances de propagação aumentadas.

As espécies da família Pipridae são na maioria das vezes, observadas se alimentando de bagas (Sick, 1984), que engolem inteiras, sendo raramente vistas arrancando pedaços de frutos para se alimentarem, embora Wheelwright et al (1984) também tenham observado uma espécie desta família, Chiroxiphia linearis, se alimentando da infrutescência de Cecropia obtusifolia, em trabalho realizado na Costa Rica. Snow (1962) observou, em Trinidad, M. manacus retirando pedaços de infrutescências de Cecropia peltata L.; neste caso o autor meniciona que o pássaro não se prende à infrutescência da qual se alimenta, ao contrário do que foi constatado para Cecropia cf. glasiovii em Juquiá.

A abundância de recursos alimentares oferecida por C. adenopus é provavelmente o fator responsável pela ausência de competição entre.as espécies que deles se utilizam, como já constatado por Leck (1972) com outras espécies. Comportamento semelhante ao verificado por Wolf (1970) entre aves migratórias e residentes foi observado nas espécies estudadas. Os poucos encontros agressivos obedeceram, em sua maioria, a uma hierarquia baseada no tamanho, com as espécies maiores sendo dominantes.

As aves envolvidas com a dispersão de $C$. adenopus freqüentam a borda da mata, favorecendo desta maneira a ornitocoria, haja visto eliminarem as sementes em uma área de maior incidência de luz.

\section{AGRADECIMENTOS}

À Maria Isabel Barros Mündell, ao Walter Mündell e a Giomar Barcellos Monari, por terem fornecido condições para a realização do trabaIho; à Prof. Prafulbala Patel pela revisão do abstract; à Profa. Eloisa 
Helena Morgado do Amaral e ao Prof. Wesley Rodrigues Silva pela leitura e discussão do texto; aos biólogos Cláudio Tiago e Valéria Flora Hadel, do CEBIMAR, pela ajuda prestada.

\section{REFERÊNCIAS}

Eisenmann, E. 1961. Favorite foods of neotropical birds: flying Termites and Cecropia catkins. Auk 78:636-638.

Jazen, D. H. 1981. Ficus ovalis seed predation by an Orange-chinned Parakeet (Brotogeris jugularis) in Costa Rica. Auk 98:841-844.

Joly, A. B. 1970. Conheça a vegetação brasileira. Polígono \& Edusp, São Paulo.

Jordano, P. 1983. Fig-seed predation and dispersal by birds. Biotropica 15(1):38-41.

Leck, C. F. 1972a. The impact of some North American migrants at fruiting trees in Panama. Auk 89:842-850.

Leck, C. F. 1972b. Seasonal changes in feeding pressures of fruit- and nectar eating birds in Panama. Condor 74:54-60.

Meyer de Schauensee, R. 1970. The birds of South America. Edinburgh. Oliver \& Boyd. 470p.

Morton, E. S. 1973. On the evolutionary advantages and disadvantages of fruit eating in tropical birds. Am. Nat. 107(953):8-22.

Phelps Jr., W. H. \& Meyer de Schauensee, R. M. de 1978. Una guia de las aves de Venezuela. Graficas Armitano, Caracas.

Sazima, I., Sazima, M. \& Semir, J. 1981. Dispersão de Moraceae por aves e mamíferos. Resumos 1. Congresso da Sociedade Botânica de São Paulo.

Silva, W. R. 1980. Notas sobre o comportamento alimentar de três espécies de Traupideos (Passeiformes: Thraupidae) em Cecropia concolor na região de Manaus. Acta Amazonica 10(2):427-429.

Snow, D. W. 1962. A field study of the Black and White Manakin, Manacus manacus, in Trinidade. Zoologia, 47:65-104.

Snow, D. W. 1971. Evolutionary aspects of fruit-eating by birds. Ibis 113:194-202.

Snow, D. N. 1981. Tropical frugivorous birds and their food plants; a world survey. Biotropica, 13: 1-14.

Trejo Perez, L. 1976. Diseminacion de semillas por aves en "Los Tuxtlas", Ver in Regeneracion de Selvas, Eds. A. Gomez-Pompa e C. Vasquez-Yanes, S. del Amo Rodrigues e A. Butanda Cevera. Compañia Editorial Continental, S/A. México.

Válio, I. F. M. \& Joly, C. A. 1979. Light sensitivity of the seeds on the distribution of Cecropia glaziovii Snethlage (Moraceae). Z. Pflanzenphysiol. Bd. 91: 371-376.

Wheelwright, N. T.; Haber, W. A.; Greg Murray, K. \& Guindon, C. 1984. Tropical fruiteating birds and their food plants: A survey of a Costa Rican lower montane forest. Biotropica, 16(3): 173-192.

Wolf, L. L. 1970. The impact of seasonal flowering on the biology of some tropical hummingbirds. Condor 72: 1-14. 